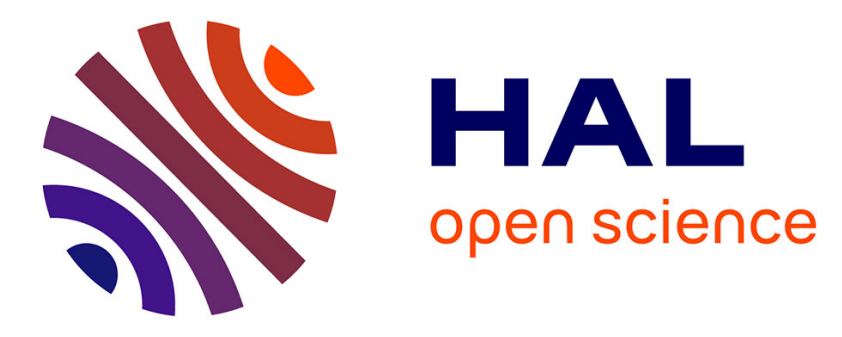

\title{
Fillers as Heaters for Photothermal Polymerization upon NIR Light
}

Aude Heloise Bonardi, Fabrice Bonardi, Frederic Dumur, Didier Gigmes, Jean

Pierre Fouassier, Jacques Lalevee

\section{- To cite this version:}

Aude Heloise Bonardi, Fabrice Bonardi, Frederic Dumur, Didier Gigmes, Jean Pierre Fouassier, et al.. Fillers as Heaters for Photothermal Polymerization upon NIR Light. Macromolecular Rapid Communications, 2019, pp.1900495. 10.1002/marc.201900495 . hal-02491523

\section{HAL Id: hal-02491523 \\ https://hal.science/hal-02491523}

Submitted on 2 Jul 2020

HAL is a multi-disciplinary open access archive for the deposit and dissemination of scientific research documents, whether they are published or not. The documents may come from teaching and research institutions in France or abroad, or from public or private research centers.
L'archive ouverte pluridisciplinaire HAL, est destinée au dépôt et à la diffusion de documents scientifiques de niveau recherche, publiés ou non, émanant des établissements d'enseignement et de recherche français ou étrangers, des laboratoires publics ou privés. 


\title{
Fillers as Heaters for Photothermal Polymerization Upon NIR Light
}

\author{
A-H. Bonardi ${ }^{1,2}$, F. Bonardi ${ }^{3}$, F. Dumur ${ }^{4}$, D. Gigmes ${ }^{4}$, J.P. Fouassier ${ }^{1}$ and J. Lalevée* ${ }^{1,2}$ \\ ${ }^{1}$ Université de Haute-Alsace, CNRS, IS2M UMR 7361, F-68100 Mulhouse, France \\ ${ }^{2}$ Université de Strasbourg, France \\ ${ }^{3}$ IBISC, Univ Evry, Université Paris-Saclay, 91025, Evry, France \\ ${ }^{4}$ Aix Marseille Univ, CNRS, ICR, UMR7273, F-13397 Marseille, France. \\ e-mail: jacques.lalevee@uha.fr
}

\begin{abstract}
:
Photoinduced thermal polymerization upon Near-Infrared light (NIR) has been reported in the literature. In this latter approach, a component able to convert the NIR light into heat must be used in combination with a thermal initiator to initiate the free-radical polymerization of (meth)acrylates. In previous recent studies, some dyes have been presented as very efficient heat generators (called heaters). In the present work, different fillers are investigated as heaters and compared to organic NIR dyes. An alkoxyamine (e.g. BlocBuilder-MA) is used as thermal initiator and will be dissociated by the heat generated by the NIR photoexcitation of the fillers. In the present work, several fillers are examined: graphene oxide, graphene nanoplatelets, multi-walled carbon nanotubes and silicon carbide. Due to the energy of the photon delivered, NIR light curing is challenging but offers several advantages compared to visible light. Notably, the most interesting feature is the deeper penetration of the light inside the photocurable resin, enabling the polymerization of thick samples. Parallel to this, incorporation of fillers in resins allows a unique access to composites through photothermal polymerization of (meth)acrylates. Three different wavelengths of irradiation have been studied: $785 \mathrm{~nm}, 940 \mathrm{~nm}$ and $1064 \mathrm{~nm}$.
\end{abstract}


Most of the photopolymerization processes involves a photoinitiator, which is a compound capable to generate polymerization initiating species (e.g. cations, anions or free radicals) after absorption of a certain wavelength of light. Thus, it is possible to transform a liquid or viscous monomer or resin into a highly crosslinked solid polymer. It allows the fabrication of a large range of materials e.g. coatings, inks, paints, adhesives, composites, 3D printed objects... However, a strong limitation of the photopolymerization technology is the low UV light penetration for the curing of filled samples and in particularly for the access to composites.[1][2] In a recent paper, we have proposed the photothermal polymerization as a first answer to overcome the problem of composites polymerization.[3] In this work, the use of a Near-Infrared light rather than a UV light was proposed, even if UV light remains extensively used in industrial photopolymerization. As a specificity of the NIR light, this wavelength range allows a deeper light penetration inside the reaction media and especially for resins containing high contents of fillers. Initiation of the polymerization process was proposed thanks to a unique combination of a thermal initiator and an organic molecule. The dyes proposed in this work were mostly based on the cyanine scaffold and could act as a lightto-heat convertor (NIR heater).

The mechanisms of light-to-heat conversion is extensively described in the literature for phototherapy applications.[4] Various organic dyes are known in the literature to be efficient for light-to-heat conversion. However, light-to-heat conversion is not restricted to organic dyes and metal components or mineral fillers can also be used. As metal components, gold nanoparticles are often used.[5] But graphene oxide is also described in the literature.[6] In recent and elegant works, free-radical polymerization initiated by carbon black nanoparticles as NIR heaters has been reported.[7] However, with carbon black particles the photothermal polymerization was much less efficient that with organic NIR dyes e.g. IR-780 borate [3]. In this communication, we propose the use of different other fillers as heaters for the polymerization of methacrylate upon NIR light exposure and compare their ability to an organic dye. The different fillers used in this work are presented in the Scheme 1: multiwalled carbon Nanotube, Graphene Nanoplatelets, Graphene oxide and Silicon Carbide. These fillers are already commonly used for composites manufacturing in industry. 


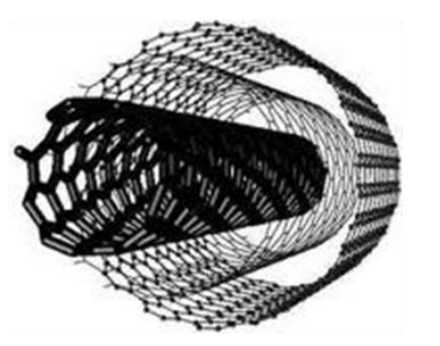

Multi-walled Carbon Nanotube $60-100 \mathrm{~nm}$ (diam. ), $>5 \mu \mathrm{m}$ (length)

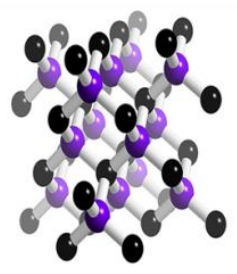

Silicon Carbide

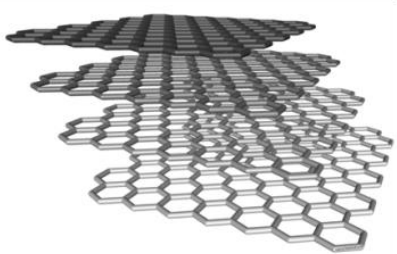

Graphene Nanoplatelets $6-8 \mathrm{~nm}$ (thick), $25 \mu \mathrm{m}$ (wide)

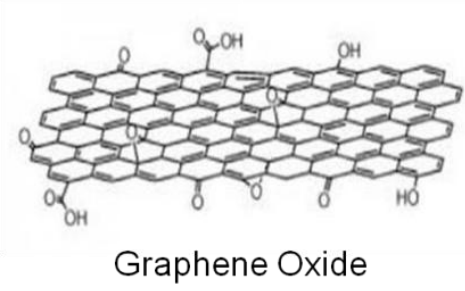

\section{SCHEME 1. FILLERS USED AS HEATERS IN THIS WORK}

Multi-walled Carbon Nanotubes are fillers which exhibit unique electronic and mechanical properties. More precisely, these compounds are characterized by their low density, high elastic modulus, strengths 10 to 100 times higher than that of the strongest steel at a fraction of the weight.[8] One application of composites with carbon nanotubes is electromagnetic shielding or antistatic.[9] Graphene Nanoplatelets are also already used for the design of nanocomposites.[10] Notably, an enhanced thermal conductivity of the corresponding epoxy composites was demonstrated upon incorporation of Graphene Nanoplatelets. As a consequence, these fillers have thus a huge potential for applications in electrical insulation with enhanced thermal conductivity.[11] Composites prepared are also lightweight and easily processed. Graphene oxide has been widely used for the design of graphene-based functional materials.[12] A graphene oxide sheet is a single graphite layer bearing various oxygenated functional groups. Graphene oxide as fillers are used to produce conducting polymers with applications in drug releasing and energy storage for example. These composites exhibit good electrochemical activity, large specific surface areas, high conductivity and biocompatibility.[12] To finish, we have also chosen silicon carbide (SiC) as fillers. It has been used for a wide variety of industrial purposes due to its high hardness and high resistivity to extremely high temperature.[13-14] $\mathrm{SiC}$ is used for cutting tools, refractory components and high-power electrical systems. SiC ceramics are already well described in the literature due to their remarkable resistance to radioactivity: these ceramics are notably used in nuclear plants.[15] 
Light-to-heat conversion abilities of these different fillers have been estimated upon irradiation to a laser diode@1064 nm. Temperature profiles associated with the photoexcitation at $1064 \mathrm{~nm}$ of the different fillers dispersed in Mix-MA (Scheme 2) are reported in the Figure 1. However, due to their filler characters, they are not soluble in the monomer and precipitate within few hours after preparation. Therefore, their use as photothermal initiators can only be carried out just after mixing. We observed that with the four tested fillers, it was possible to reach a temperature higher than $60^{\circ} \mathrm{C}$, temperature which is necessary for the homolysis of the thermal initiator (BlocBuilder-MA in Scheme 2) and its initiation of the benchmark methacrylate blend (Mix-MA - Scheme 2).[3] However, from the temperature profiles, the best heaters are Graphene Nanoplatelets > Multi-walled Carbon Nanotubes $\sim$ Graphene oxide $\gg \mathrm{SiC}$ (Figure 1). Indeed, after 30s of irradiation, only the first three fillers are able to generate more than $60^{\circ} \mathrm{C}$ in Mix-MA i.e. $\mathrm{SiC}$ is associated with a slower temperature increase (Figure 1, curve 4).
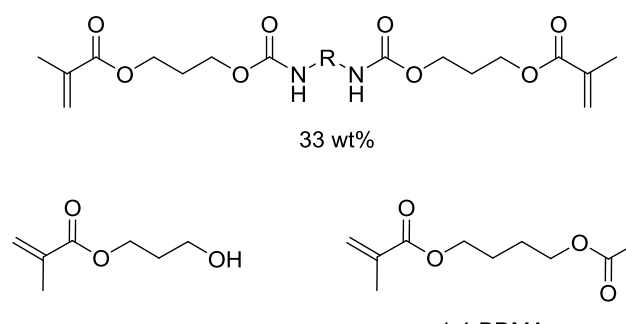

HPMA $33 \mathrm{wt} \%$

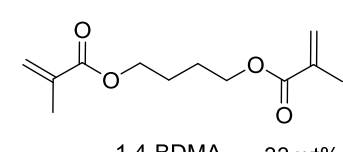

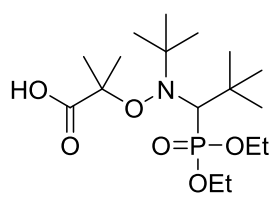

BlocBuilder ${ }^{\circledR}$ MA

Scheme 2. Chemical structure of the monomers in the benchmark methacrylate blend (MixMA) and the thermal initiator BlockBuilder-MA. 
Figure 1. TEMPERATURe PROFILES OF MiX-MA UNDER AIR (TEMPERATURE OF THE SAMPLE VS. IRRADIATION TIME) IN THE PRESENCE OF 0.1 W\% (1) MULTI-WALLED CARBON Nanotubes, (2) Graphene oxide, (3) Graphene Nanoplatelets, (4) Silicone CARBIDE, IRRADIATION WITH A LASER DIODE@1064 NM AT 2W/CM²; THICKNESS=10MM; THE IRRADIATION STARTS AT $\mathrm{T}=17 \mathrm{~s}$.

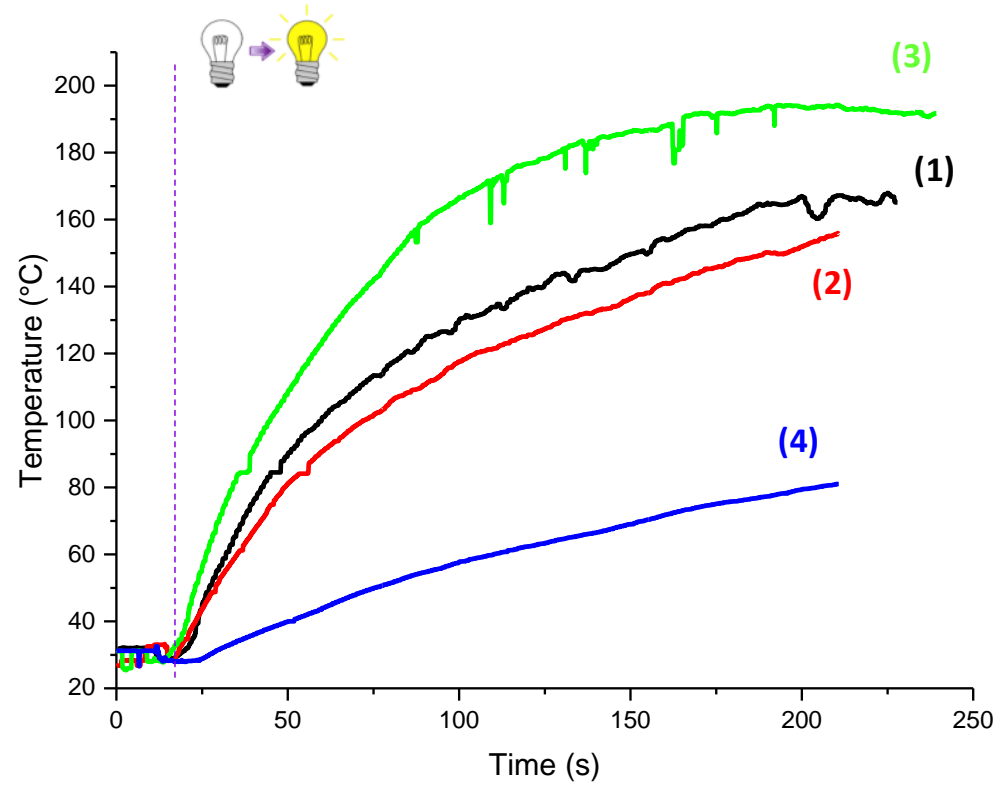

The formulations with graphene oxide visually exhibiting a better homogeneity of the dispersions than with the other fillers (Graphene Nanoplatelets, Multi-walled Carbon Nanotubes and silicon carbide) for which a rapid precipitation of fillers could be observed, this filler was selected for the photothermal polymerization experiments (i.e. using $0.1 \mathrm{wt} \%$ ) in combination with $2 \mathrm{wt} \%$ of BlocBuilder-MA as the thermal initiator in the Mix-MA resin. Three wavelengths of irradiation have been tested: @785 nm, @940 nm and @1064 nm. As shown in the Figure 2, the photopolymerization is particularly successful using the Laser Diode at $1064 \mathrm{~nm}$ : the polymerization starts very rapidly when the Laser Diode is turned on. However, the two other NIR wavelengths (785 and $940 \mathrm{~nm}$ ) of irradiation were also efficient with high final methacrylate function conversions (>75\%) for multifunctional monomers. 
FigURE 2. POLYMERIZATION PROFILES OF MIX-MA UNDER AIR (METHACRYLATES FUNCTION CONVERSION VS. IRRADIATION TIME) IN THE PRESENCE OF GRAPHENE OXIDE (0.1WT\%) AND BLOCBUILDER-MA (2WT\%) UPON IRRADIATION TO (1) LASER DIODE@ 785 NM, (2) LASER DIODE@940 NM, (3) LASER DIODE@1064 NM, THICKNESS=1.4MM; THE IRRADIATION STARTS AT T $=17 \mathrm{~s}$.

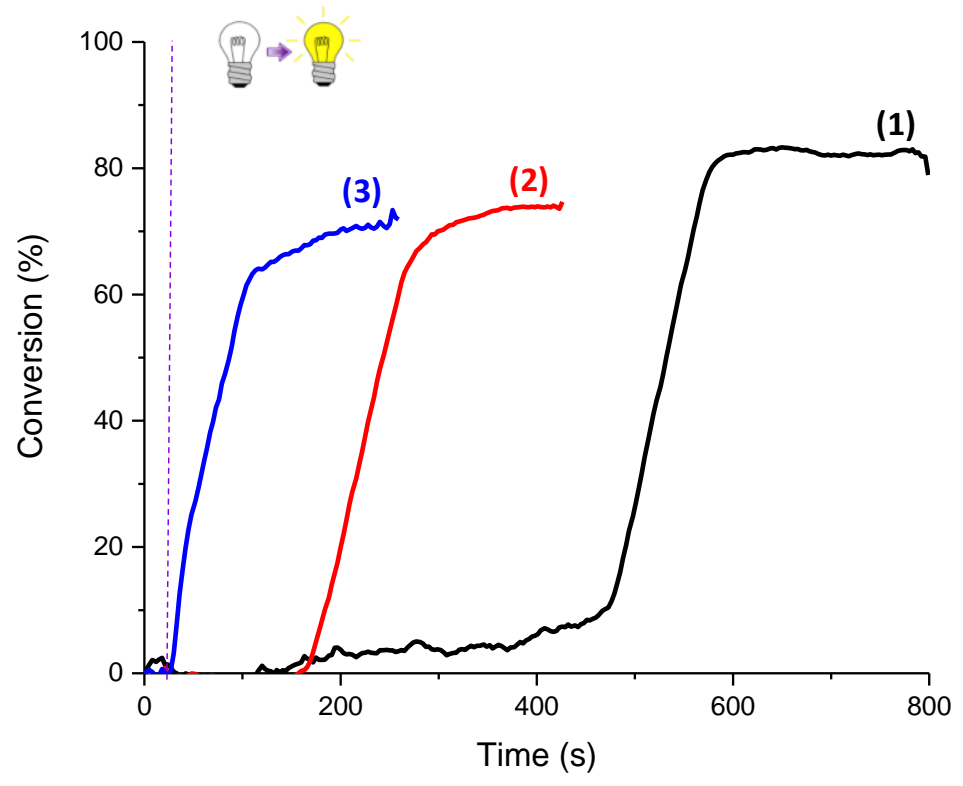

The mechanism of polymerization is the same as for the photothermal polymerization previously reported with an organic NIR dye used as a light-to-heat convertor (in [3]). The polymerization starts when the temperature reaches $50-60^{\circ} \mathrm{C}$ corresponding to the activation temperature of Blocbuilder-MA. Thus, the initiating radicals are formed, allowing the initiation step of polymerization to occur. The mechanism is presented in the Scheme 3. Here, the filler acts as a light-to-heat convertor: through irradiation with a NIR light, the filler releases heat. Remarkably, graphene oxide is a better NIR heater than carbon black nanoparticles reported in [7] to initiate polymerization reaction; indeed, the photothermal effect of carbon black particles in Mix-MA was reported low in these conditions in [3]. 


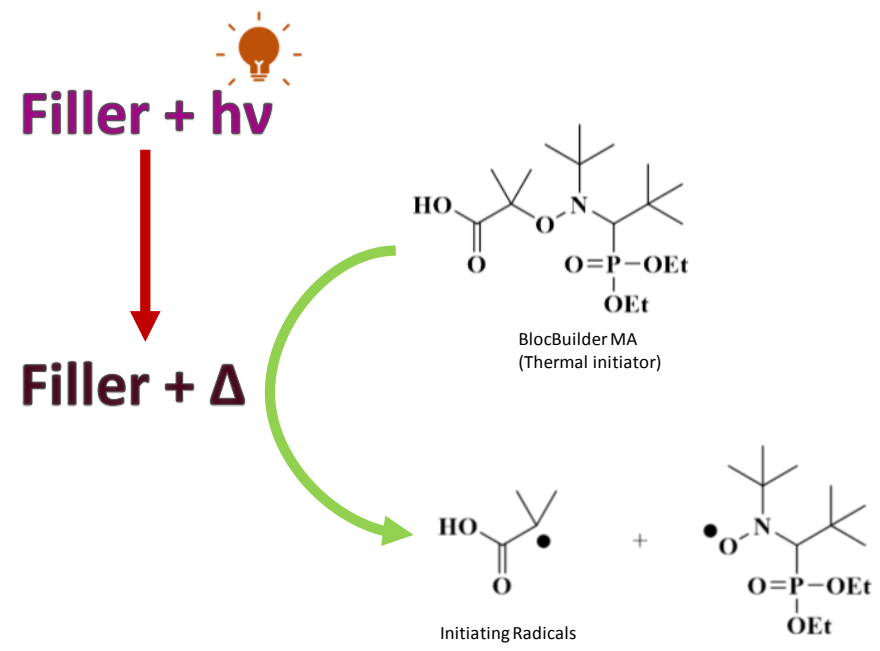

Then, the heater behavior of graphene oxide is compared to those of organic NIR dyes that have the huge advantages to be fully soluble and stable in organic monomers [3]. The dye Ir-780 borate (Figure 3) proposed by us in [3] was selected for such a comparison (from its excellent heater behavior). As shown in Figure 3, faster light-to-heat conversion is observed for the organic dye (e.g. $100^{\circ} \mathrm{C}$ is reached after less than 30 s of irradiation for the NIR dye vs. 60s for graphene oxide; Figure 3: curves 2 vs. 1). This is in agreement with the higher final methacrylate function conversion for Ir-780 borate/Blocbuilder-MA vs. grapheneoxide/Blocbuilder-MA ( $75 \%$ vs. $65 \%$ after $100 \mathrm{~s}$ of irradiation). 
FIGURE 3. THERMAL IMAGING PHOTOPOLYMERIZATION FOLLOW-UPS (TEMPERATURE VS. IRRADIATION TIME; 1.4 MM SAMPLE) UNDER AIR IRRADIATION FOR MIX-MA IN THE PRESENCE OF BLOCBUILDER-MA (2W\%) AND (1) IR-780 BORATE (0.1W\%) UPON IRRADIATION AT 785 NM (2) GRAPHENE OXIDE (0.1W\%) UPON IRRADIATION AT 1064 NM; IRRADIATION STARTS AFTER $17 \mathrm{~s}$.

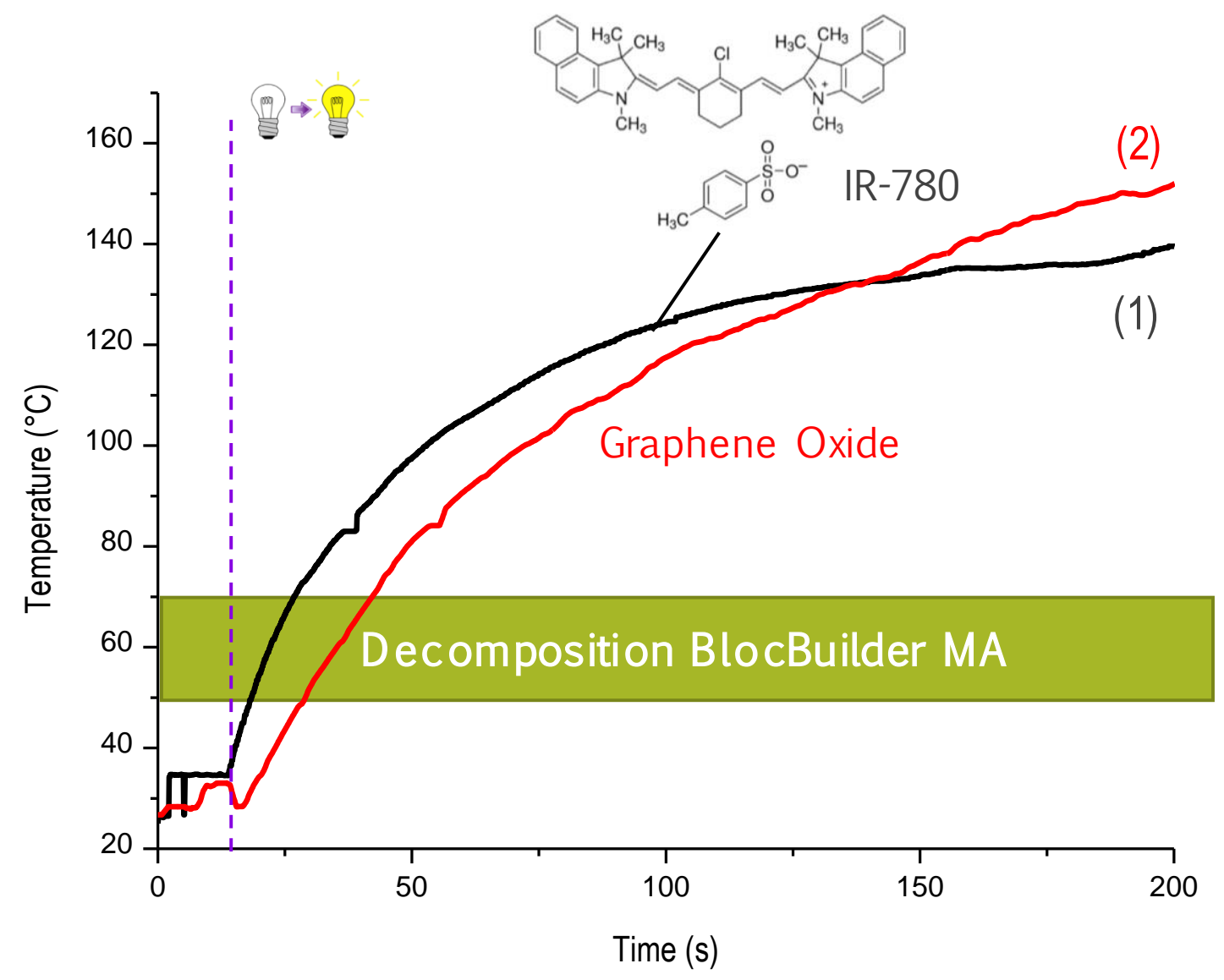

In conclusion, these preliminary experiments demonstrate the ability of fillers such as graphene oxide to initiate a photothermal polymerization upon NIR light excitation. Thanks to the temperature measurements, good polymerization efficiencies were anticipated and found experimentally. These initial results are encouraging for composites manufacturing upon NIR light irradiation; however, the organic NIR dyes approach as heaters remains the privileged one with good solubility and stability (without any precipitation) in organic monomers associated with higher photothermal effect. The use of NIR for the curing of carbon or glass fibers composites with high depth of cure will be presented in forthcoming works. 


\section{Experimental part:}

Compounds: Multi-walled Carbon Nanotube, Graphene Nanoplatelets, Silicon Carbide, Graphene Oxide (Scheme 1) have been purchased from Sigma-Aldrich. Ir-780 (Figure 3) has been purchased from Sigma-Aldrich. The benchmark monomer "Mix-MA" is a mixture of (hydroxypropyl)methacrylate (HPMA, 33w\%), 1,4-butanediol dimethacrylate (1,4-BDMA, $33 \mathrm{w} \%$ ) and urethane dimethacrylate monomer (UDMA, 33w\%), obtained from Sigma Aldrich and represented in Scheme 2. Ir-780 borate was synthesized as previously reported in the literature, without modification and in similar yield [3].

Thermal imaging experiments: an infrared thermal imaging camera Fluke TiX500 was used for thermal imaging experiments. The thermal images were extracted using a Fluke SmartView4.1 Data and then batch processed using a script written in Python. The procedure has been described more in detail in [16].

RT-FTIR polymerization kinetics: a Real-Time Fourier Transform Infrared (RT-FTIR) spectrometer (Jasco 4600) was used to follow the kinetics of polymerization. The follow of the band located at $6100-6220 \mathrm{~cm}^{-1}$ is directly related to the double bond $\mathrm{C}=\mathrm{C}$ conversion. Polymerization is performed in a mold (1.4 mm thick), under air by irradiation with a laser diode. Laser is turned on 17 seconds after the first spectra measurements in order to have a baseline. Details for each experiment are given in the figures caption of the concerned experiment. The procedure has been described more in details in [17].

\section{$\underline{\text { Acknowledgements }}$}

The authors gratefully acknowledge the financial support from the ANR agency and for the grant "ANR FastPrinting”.

\section{Conflict of interest}

The authors declare no conflict of interest.

\section{$\underline{\text { Keywords }}$}

Fillers, photothermal effect, graphene oxide, photopolymerization, NIR light, photoinitiator. 


\section{References}

[1] Fouassier, J. P.; Lalevée, J. Photoinitiators for Polymer Synthesis-Scope, Reactivity, and Efficiency, Wiley-VCH Verlag GmbH \& Co KGaA, Weinheim 2012.

[2] Xiao, P; Zhang, J.; Dumur, F.; Tehfe, M.-A.; Morlet-Savary, F.; Graff, B; Gigmes, D; Fouassier, J.-P.; Lalevée, J; Visible light sensitive photoinitiating systems: Recent progress in cationic and radical photopolymerization reactions under soft conditions.. Prog. Polym. Sci. $2015,41,32$.

[3] Bonardi, A.-H.; Bonardi, F.; Morlet-Savary, F.; Dietlin, C.; Noirbent, G.; Grant, T. M.; Fouassier, J.-P.; Dumur, F.; Lessard, B. H.; Gigmes, D.; et al. Photoinduced Thermal Polymerization Reactions. Macromolecules 2018, $51 \quad$ (21), 8808-8820. https://doi.org/10.1021/acs.macromol.8b01741.

[4] Yuan, A.; Wu, J.; Tang, X.; Zhao, L.; Xu, F.; Hu, Y. Application of Near-Infrared Dyes for Tumor Imaging, Photothermal, and Photodynamic Therapies. Journal of pharmaceutical sciences 2013, 102 (1), 6-28.

[5] Huang, X.; Jain, P. K.; El-Sayed, I. H.; El-Sayed, M. A. Plasmonic Photothermal Therapy (PPTT) Using Gold Nanoparticles. Lasers in medical science 2008, 23 (3), 217-232.

[6] Tian, B.; Wang, C.; Zhang, S.; Feng, L.; Liu, Z. Photothermally Enhanced Photodynamic Therapy Delivered by Nano-Graphene Oxide. ACS nano 2011, 5 (9), 7000-7009.

[7] Steinhardt, R. C.; Steeves, T. M.; Wallace, B. M.; Moser, B.; Fishman, D. A.; Esser-Kahn, A. P. Photothermal Nanoparticle Initiation Enables Radical Polymerization and Yields Unique, Uniform Microfibers with Broad Spectrum Light. ACS Appl. Mater. Interfaces 2017, 9 (44), 39034-39039

[8] Thostenson, E. T.; Ren, Z.; Chou, T.-W. Advances in the Science and Technology of Carbon Nanotubes and Their Composites: A Review. Composites science and technology 2001, 61 (13), 1899-1912.

[9] Khan, W.; Sharma, R.; Saini, P. Carbon Nanotube-Based Polymer Composites: Synthesis, Properties and Applications. In Carbon Nanotubes-Current Progress of their Polymer Composites; IntechOpen, 2016.

[10] Young, R. J.; Liu, M.; Kinloch, I. A.; Li, S.; Zhao, X.; Vallés, C.; Papageorgiou, D. G. The Mechanics of Reinforcement of Polymers by Graphene Nanoplatelets. Composites Science and Technology 2018, 154, 110-116.

[11] Jarosinski, L.; Rybak, A.; Gaska, K.; Kmita, G.; Porebska, R.; Kapusta, C. Enhanced Thermal Conductivity of Graphene Nanoplatelets Epoxy Composites. Materials SciencePoland 2017, 35 (2).

[12] Bai, H.; Sheng, K.; Zhang, P.; Li, C.; Shi, G. Graphene Oxide/Conducting Polymer Composite Hydrogels. J. Mater. Chem. 2011, 21 (46), 18653-18658.

[13] Naslain, R. R. SiC-Matrix Composites: Nonbrittle Ceramics for Thermo-Structural Application. International Journal of Applied Ceramic Technology 2005, 2 (2), 75-84.

[14] Halloran, J. W. Ceramic Stereolithography: Additive Manufacturing for Ceramics by Photopolymerization. Annual Review of Materials Research 2016, 46, 19-40. 
[15] Lee, S.-K.; Ishida, W.; Lee, S.-Y.; Nam, K.-W.; Ando, K. Crack-Healing Behavior and Resultant Strength Properties of Silicon Carbide Ceramic. Journal of the European Ceramic Society 2005, 25 (5), 569-576.

[16] Garra, P.; Bonardi, A.-H.; Baralle, A.; Al Mousawi, A.; Bonardi, F.; Dietlin, C.; MorletSavary, F.; Fouassier, J.-P.; Lalevée, J. Monitoring Photopolymerization Reactions through Thermal Imaging: A Unique Tool for the Real-Time Follow-up of Thick Samples, 3D Printing, and Composites. Journal of Polymer Science Part A: Polymer Chemistry 2018, 56 (8), 889-899.

[17] Bonardi, A.-H.; Bonardi, F.; Morlet-Savary, F.; Dietlin, C.; Noirbent, G.; Grant, T. M.; Fouassier, J.-P.; Dumur, F.; Lessard, B. H.; Gigmes, D.; et al. Photoinduced Thermal Polymerization Reactions. Macromolecules 2018, $51 \quad$ (21), 8808-8820. https://doi.org/10.1021/acs.macromol.8b01741. 